\title{
Simulation Analysis of Spherical Mechanical Seal Property of Marine Stern Shaft
}

\author{
Xu Hui ZHOU ${ }^{\text {a }}$, Li ZOU \\ School of Energy and Power Engineering, Wuhan University of Technology, Wuhan 430063, China
}

\begin{abstract}
The finite element model of spherical mechanical seal wasestablished with ANSYS, and the influence of seawater pressure, shaft speed and other factors on the sealing performance was discussed. The studyresults show that local contact situation of the spherical mechanical seal is in the outside of the seal rings, and both maximum contact pressure and temperature appearat the same position.As seawater pressure and stern shaft rotary speed are increased, the contact pressure and temperature of the spherical seal surface are raised, and when the contact pressure of seal surface is 0 , the spherical seal surface formstwo zones including contact one and clearance zone.The former is near the outside of the seal ring, the lateris close to the inside of one.These research results are of important theoretical significance and engineering application value for the development of new kinds of mechanical seals, and improvement of both safety and survivability of underwater vehicles.
\end{abstract}

\section{Introduction}

Stern shaft mechanical seal is an important device of underwater vehicle, whichcan affect seriously the safety and survival ability of underwater vehicles.

At present, domestic and abroad stern shaft seal of underwater vehicles adopts plane mechanical seal device, whose performance depends mainly on the materials of rotary andstator rings, and contact state of the friction pair. The material of rotary ringis hard alloy, while oneof stator ring is graphite carbon. Marine mechanical seal device is generally a kind of contact seal, and operates much in mixed friction state. British Deep Sea Seal L.t.d, USA SealLoLL.t.d, USA Durametallioc Co, Japanese Engle and some domestic companies did a lot of research work about mechanical seal, which made considerable progress. But because of the clearance between the stern shaft and stern bearing, plane mechanical seal elements appear radial runoutwhile working. The situation,such as wear of the stern bearing and sinks or bends of the stern shaft, is more serious; it results in overrunleakage, and affects seriously influence the reliability and safety of the propulsion systemof the vehicle.

Christophe Minet ${ }^{[1]}$ points out, the mix lubricationof mechanical seal is complex, andrelative test research is less. In Andre' Parfait's study ${ }^{[2,3]}$, he discussed theory calculation model,heat conduction, deformation, mixed lubrication region of seal rings, and so on. Theory analysis and calculation have applied on plane mechanical seal. Through a lot of experiments, E.Mayergot that the liquid film between two sealing surfaces of general mechanical seal rings is too thin, Newton fluid equations is a lack of effective application conditions, and sealing surfacesare in boundary lubrication state $^{[4]}$.In order to obtain the flow field, temperature fieldand main influence factorsof the mechanical seal, Dazhuan $\mathrm{Wu}^{[5]}$ put forward that mechanical seal numerical analysis in high pressure, high temperature, and high speed should be carried out.

\footnotetext{
${ }^{a}$ Xu Hui ZHOU: 923309503@qq.com
} 
GuopingYAN ${ }^{[6]}$ gave the calculation expression of friction heatof sealing end face, deduced the friction coefficient of the end face in mixed friction state, analyzed the shortage of the calculation method of convective heat transfer coefficient, and gave a new calculation formula of inside and outside of rotary, stator ring's heat transfer coefficients. In the steady thermal-structure coupling analysis of mechanical seal rings, Zhu Xueming ${ }^{[7]}$ made the direct coupling on the thermal structure field and simulationof the stress, temperature and deformation. Lu Sheng ${ }^{[8]}$ carried out the research of dam surface mechanical seal, analyzed the influence levels of narrow seal structures on stress, temperature and deformation.

Overall, at present, there is no report about the theory analysis research on marine spherical mechanical seal. The difference between the spherical mechanical seal and the plane onelies in that the former structure takes spherical contact instead of plane contact, which can automatically adjust the seal surface contact status, enhance the tracing ability of the seal friction pair and make the spherical seal surface of bothrotary andstatorrings keep consistentlyin contact state. Therefore,spherical mechanical seal can be used to solve the above practical problems and to improvethe mechanical seal performances.

\section{Spherical mechanical seal}

The spherical mechanical seal is composed of a rotary ring, rotary ringseat, stator ring, stator ring seat, spring,spring seat and other componentsuch as stern shaft, fix ring, as shown in Figure 1.

The cemented carbiderotary ring is embedded in the rotary ringseat, and the rotary ringseat is fixed on the stern shaftand rotates with the shaft; the stator ring made of nonmetal material (FEROFORM) is fixed on the stator ringseat, and can move axially with the seat along stern shaft.FEROFORM is taken as the stator ringmaterial of the spherical mechanical seal instead of the commonly used graphite carbon, which can effectively improve both wear uniformity and wear resistanceof the contact surface.

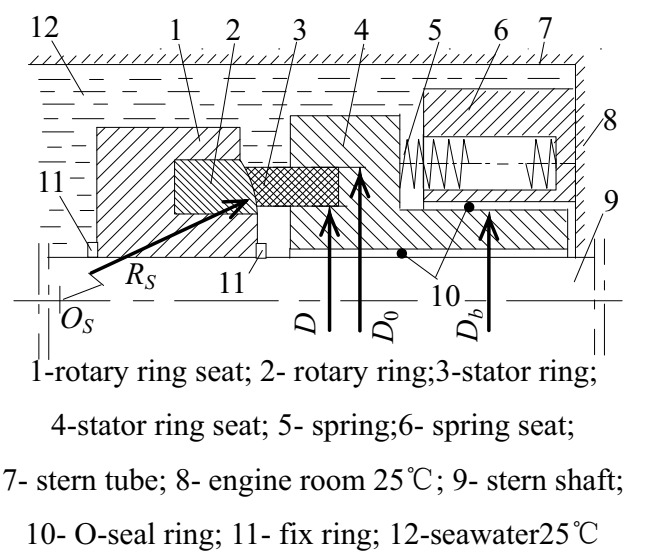

Figure.1 Spherical mechanical seal drawing

The contact surface between rotary and stator rings is a spherical one that can plays a sealing role and has self-aligningfunction. The both spring force and pressure of sealed medium (seawater) can ensure the sphericalseal surfaceof bothrotary and the stator rings tobe consistentlycontacted so thatseawater is sealed outside of the spherical sealsurface, while air inside of one.

The ratio of areaof effective fluid pressure of the spherical mechanical seal to one ofsealing contact pressure is 0.634 , which indicates that the seal is balance type. The width of spherical seal is $8 \mathrm{~mm}$; the spherical contact area is $5275.2 \mathrm{~mm}^{2}$.

The specific pressure of spring is 0.2 MPa.The key structure and material parameters of the spherical mechanical seal are listed in Table land Table 2.

Table 1 Key structure parameter of spherical seals

\begin{tabular}{|c|c|c|c|c|c|c|c|}
\hline Seal type & $\begin{array}{c}\text { Shaft } \\
\text { diameter } \\
D / \mathrm{mm}\end{array}$ & $\begin{array}{c}\text { Inside } \\
\text { diameter of } \\
\text { seal ring } \\
D_{\mathrm{i}} / \mathrm{mm}\end{array}$ & $\begin{array}{c}\text { Outside } \\
\text { diameter of } \\
\text { seal ring } \\
D_{\mathrm{o}} / \mathrm{mm}\end{array}$ & $\begin{array}{c}\text { Slip } \\
\text { diameter } \\
D_{\mathrm{b}} / \mathrm{mm}\end{array}$ & $\begin{array}{c}\text { Sealing } \\
\text { spherical } \\
\text { radius } \\
R_{\mathrm{S}} / \mathrm{mm}\end{array}$ & \multicolumn{2}{|c|}{$\begin{array}{c}\text { Seal surface } \\
\left(^{\circ}\right)\end{array}$} \\
\hline Spherical seal & 185 & 202 & 218 & 208 & 200 & $\theta_{1}$ & $\theta_{2}$ \\
\hline
\end{tabular}


Table 2 Physical parameter of materials of seal rings and their seats

\begin{tabular}{|c|c|c|c|c|c|c|c|c|}
\hline Item & Material & $\begin{array}{c}\text { Modulus of } \\
\text { elasticity } \\
E / \mathrm{MPa}\end{array}$ & $\begin{array}{c}\text { Poisson's } \\
\text { ratio } \\
\mu\end{array}$ & $\begin{array}{c}\text { Coefficient of } \\
\text { thermal } \\
\text { conductivity } \\
\lambda / \mathrm{W} /(\mathrm{m} \cdot \mathrm{K})\end{array}$ & $\begin{array}{c}\text { Linear } \\
\text { expansion } \\
\text { coefficient } \\
a /\left(\mathrm{m} /{ }^{\circ} \mathrm{C}\right)\end{array}$ & $\begin{array}{c}\text { Density } \\
\rho /\left(\mathrm{kg} / \mathrm{m}^{3}\right)\end{array}$ & $\begin{array}{c}\text { Maximum } \\
\text { permissible } \\
\text { temperature } \\
/{ }^{\circ} \mathrm{C}\end{array}$ & $\begin{array}{c}\text { Friction } \\
\text { Coefficient } \\
f\end{array}$ \\
\hline Stator ring & Feroform & 300 & 0.48 & 0.5 & $70 \times 10^{-6}$ & $1.32 \times 10^{3}$ & 120 & 0.03 \\
\hline Rotary ring & bronze & $\begin{array}{c}11.5 \times 10 \\
4\end{array}$ & 0.32 & 63.8 & $17.8 \times 10^{-6}$ & $8.5 \times 10^{3}$ & & \\
\hline $\begin{array}{c}\text { Stator or } \\
\text { rotary } \\
\text { ring seat }\end{array}$ & $\mathrm{C} 15$ & $\begin{array}{c}19.8 \times 10 \\
4\end{array}$ & 0.29 & 16.33 & $16.6 \times 10^{-6}$ & $7.9 \times 10^{3}$ & \\
\hline
\end{tabular}

\section{Finite element model}

\subsection{Thermal-structure model}

The thermal-structure finite element model of the spherical mechanical sealis established with ANSYS software, which is a type of axial symmetrymodel as shown in Figure 2. The model includes 3069 elements, 3191 nodes in all.

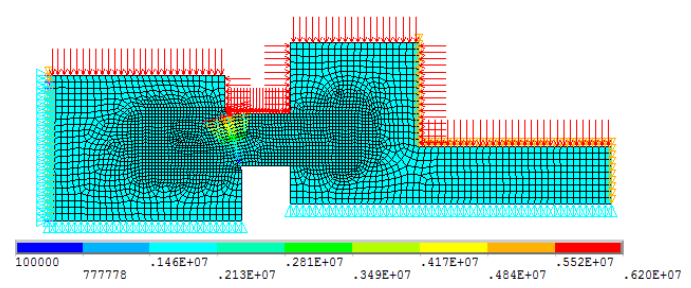

Figure 2.Finite element model of spherical seal

Assume that the spring pressure and external pressure of seawater are uniformly distributed, and the reaction force of seawater film between spherical sealsurfaces is in linear distribution; the fluid cooling of the sealing rings is dealt with according to convection heat transfer boundary; the friction heat between spherical seal surfaces is definedas heat flux boundary.

Seal contact surface is defined on the spherical seal surface of both rotary andstator rings. Contact unit is defined on the spherical seal surface of the stator ring by application of contact guide, and target unit is defined on the spherical seal surface of the rotary ring. Thus the automatic distribution of heat flux density can be realized and the corresponding node temperature of the spherical seal surfacesof both rotary and stator rings is guaranteed to be basically consistent.

\subsection{Convective heat transfer coefficient}

The convective heat transfer coefficient is expressed as follows:

$$
h_{m}=\frac{\lambda_{f}}{d} N u_{f}
$$

Where $d$ is external diameter of rotary ring or internal diameter of stator ring, $\mathrm{m} ; \lambda_{f}$ is the thermal conductivity of the fluid, $2.63 \mathrm{~W} /(\mathrm{m} \cdot \mathrm{K})$ for air, $60.85 \mathrm{~W} /(\mathrm{m} \cdot \mathrm{K})$ for seawater; $N u_{f}$ is theNusseltnumber.

\subsection{Boundary constraints}

The boundary constraintof the finite element modelis shown in Figure 1. Constant temperature load $25^{\circ} \mathrm{C}$ is applied on the regioncontacted with seawater of both rotary and stator ringseats; constant air temperature load $25{ }^{\circ} \mathrm{C}$ is applied on the region of both rotary andstator ringseatsfarfrom the sphericalseal surface.

The calculation formula of heat fluxdensity $q$ of seal ring is shownas follow:

$$
q=\frac{2 \pi n}{60} f \cdot p_{c}(r) \cdot r
$$

Where $q$ is heat flux density, $\mathrm{W} / \mathrm{m}^{2}$; $f$ is coefficient of friction; $p_{\mathrm{c}}(r)$ is the contact pressure between the spherical seal surfaces of two rings, $\mathrm{Pa} ; r$ is the $\operatorname{radius}(X$ direction) of seal ring, $\mathrm{m} ; n$ is a rotary ring rotation speed, $r \cdot \min ^{-1}$.

\section{Performance analysis of seal ring}

Theperformanceanalysis ofthe spherical mechanical seal ringsincludestemperature, deformation, contact pressure of the spherical mechanical sealand their influence factors.

\subsection{Temperature of sealing surface}

The highest temperature of the spherical mechanical seal is influencedbyboth seawater pressure and rotaryspeed on as shown in Table 3. 
Table 3 The highest temperature of seal $\left({ }^{\circ} \mathrm{C}\right)$

\begin{tabular}{|c|c|c|c|c|c|c|}
\hline \multirow{2}{*}{$\begin{array}{c}\text { Shaft rotary } \\
\text { speed/(r/min })\end{array}$} & \multicolumn{6}{|c|}{ Seawater pressure/ MPa } \\
\cline { 2 - 7 } & 1 & 2 & 3 & 4 & 5 & 6 \\
\hline 50 & 28.5 & 29.8 & 31.0 & 32.2 & 33.4 & 34.6 \\
\hline 100 & 32.0 & 34.5 & 36.9 & 39.4 & 41.6 & 44.0 \\
\hline 150 & 35.4 & 39.1 & 42.8 & 46.3 & 49.7 & 53.3 \\
\hline 200 & 38.7 & 43.6 & 48.5 & 53.2 & 57.7 & 62.5 \\
\hline 250 & 42.0 & 48.1 & 54.1 & 60.0 & 65.5 & 71.5 \\
\hline 300 & 45.3 & 52.5 & 59.7 & 66.7 & 73.3 & 80.4 \\
\hline
\end{tabular}

It can be seen inTable 3, that with the increase of seawater pressureor the rotary speed of stern shaft, thehighest temperature of the spherical seal surface is raised. The higher seawater pressure or rotary speedis, the

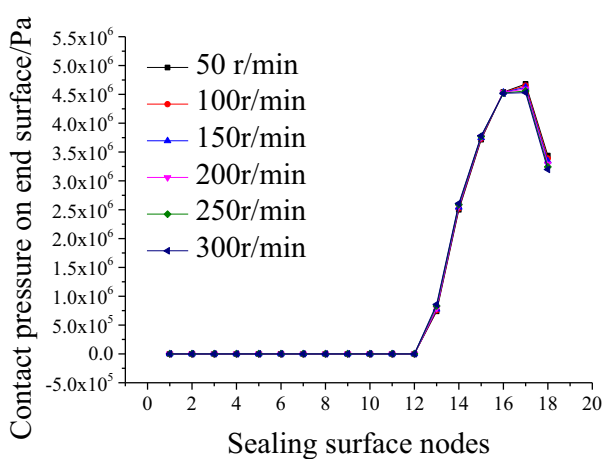

Figure 3. Contact pressure - rotary speed

In Figure 3, it can be seenthat the contact pressure of each spherical seal surface node is almost the samein different rotary speeds. The contact pressures are 0 in the region where the node number is less than 12 , which indicates clearance exists in the region.

InFigure 4, it shows thatthe trend of axial deformations of the stator ring are the same along with node numberof the spherical seal surface in different rotary speeds, and the deformation decreases with the increase of the node number. When the node number is constant, the axial deformations of node areincreasedwith the enhancement of the rotary speed.

\subsection{Discuss}

Effects of seawater pressure on deformation and contact pressure should be seriously discussed.

When pressure of seawater $1 \sim 6 \mathrm{MPa}$ and rotary speed is $300 \mathrm{r} / \mathrm{min}$, the axial deformation distribution of the stator ring is shown in Figure 5, and the contact pressure more obvious temperatureincrease is.

\subsection{Contact pressure and deformation of sealing surface}

The elastic modulus of the stator ring (300MPa) ismuch lower than that of the rotary ring $\left(11.5 \times 10^{4} \mathrm{MPa}\right)$ so thatthe deformation of the stator ring is larger.Therefore, the stator ring is only discussed.

When seawater pressure is $6 \mathrm{MPa}$ and rotary speed of stern shaft is 50, 100, 150, 200, 250, 300 $\mathrm{r} \cdot \mathrm{min}^{-1}$ respectively, both contact pressure and axial deformation of the stator ring are shown in Figure 3 and Figure 4 separately.

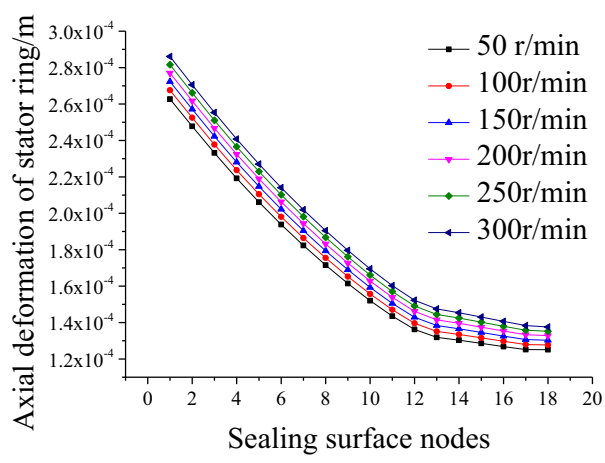

Figure 4.Axial deformation - rotary speed

distribution in Figure6.

Figure 5 shows that under different seawaterpressure, the axial deformations of the stator ringis decreasedand tended to convergence with the increase of seal surface node number. The greater the pressure is, the more obviously the deformation is decreased.

Figure 6 illustrates that the contact pressure of some nodes near the inside is 0 , and in certain node regionthe contact pressure is increased gradually with the increase of node number,but decreases correspondingly at the last two or threenodes. With the increase of seawater pressure, the contact pressure of each spherical surface node increasescorrespondingly,the number of nodes whose pressure is 0 is gradually decreased, and both maximum axial deformation and contact pressure of the stator ring are increased by almost 6 times when seawater pressure alters from 1 6 $\mathrm{MPa}$.

When the contact pressure of seal surface is 0 , it means 
thespherical seal surface formstwo zones including contact one outside the rings and clearance zoneinside the

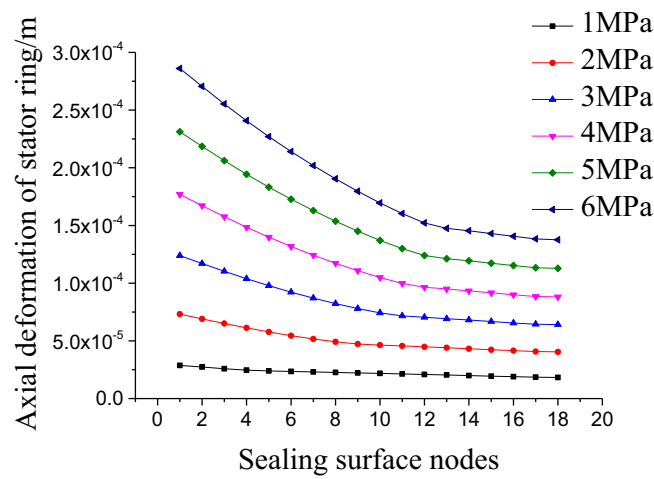

Figure 5. Seawater pressure - axial deformation

\section{Conclusion}

1) Axial deformation of spherical seal surface forms contact zone (outside the rings) and clearance zone(inside the rings). With the increase of seawater pressure and rotary speed, thedeformation of spherical seal surface increases, contact area is reduced and clearanceoneis increased.

2) As seawater pressure and rotary speed are raised, both contact pressure and temperature are increased. The maximum contact pressure and the higher temperature are near the outside of seal rings, but their valuesarein the allowed range of Feroformmaterial properties of stator ring.

\section{Acknowledgements}

It is aproject supported by the project of Key Natural Science Foundation of China (No.51139005), Natural Science Foundation of China (No.51379168).

\section{References}

1. C.Minet, A Deterministic Mixed Lubrication Model or Mechanical Seals, Journal of Tribology, Vol. 133, 1-13(2011)

2. A. P.Nyemeck, N.Brunetière, B.Tournerie. A Multiscale Approach to the Mixed Lubrication rings.

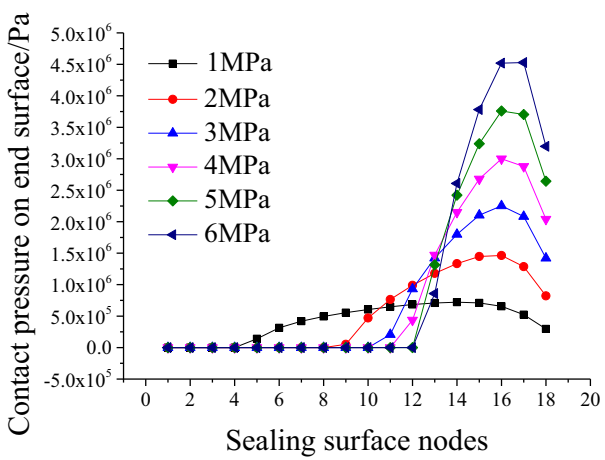

Figure 6.Seawater pressure - spherialcontact pressure

Regime: Application to Mechanical Seals, TribolLett47, 417-429 (2012)

3. A. P. Nyemeck1, N.Brunetière, B.Tournerie, Parametric study of the behavior of a mechanical face seal operating in mixed and TEHD lubrication regimes,ESDA2012, July 2-4, (2012)

4. J. Sun, Wei Long, B. Gu, Development Course and Research Trend on the Mechanical Seal, lubrication engineering, 4, 128-131(2004)

5. D. Wu, X. Jiang, S. Yang, Three Dimensional Coupling Analysis of Flow and Thermal Performance of a Mechanical Seal Journal of Thermal,Science and Engineering Applications, Vol. 6, 1-9(2014)

6. G.YAN, Z. LIU, X.ZHU,Numerical Analysis of the Thermal- field of Ship Stern- Shaft Mechanical Sealed Faces under the Variational Working Conditions,Journal of Ship Mechanics. 12, 483-489(2008)

7. G.YAN, Z. LIU, X.ZHU,Numerical Analysis of the Thermal- field of Ship Stern- Shaft Mechanical Sealed Faces under the Variational Working Conditions,Journal of Ship Mechanics. 12, 483-489(2008)

8. S. LU, Z. LIU, M. DAI, Performance analysis of dam sealing based on ANSYS,Machinery Design \& Manufacture, 6, 206-208(2011) 